\title{
Quick guide to type 2 diabetes self-management education: creating an interdisciplinary diabetes management team
}

This article was published in the following Dove Press journal: Diabetes, Metabolic Syndrome and Obesity:Targets and Therapy

\section{Brittannie Chester' \\ Wayne G Stanely² \\ Thangiah Geetha ${ }^{1,3}$}

'Department of Nutrition, Dietetics, and Hospitality Management, Auburn University, Auburn, AL 36849, USA; ${ }^{2}$ Primary Care, Florence, AL 35630, USA; ${ }^{3}$ Boshell Metabolic Diseases and Diabetes Program, Auburn University, Auburn, AL 36849, USA

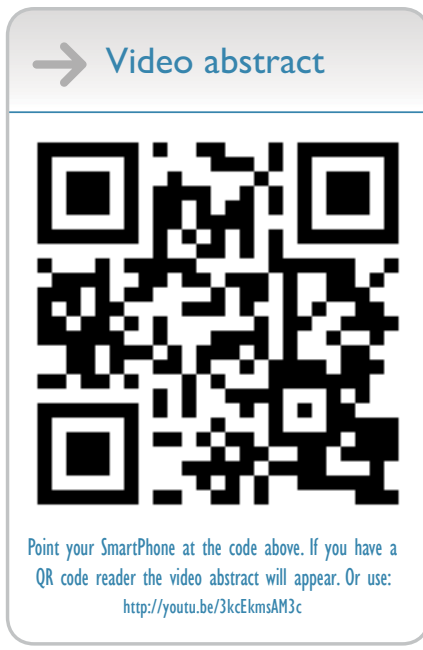

Correspondence: Thangiah Geetha Department of Nutrition, Dietetics, and Hospitality Management, I0IB Poultry Science Building, 260 Lem Morrison Drive, Auburn University, Auburn, AL 36849, USA

Tel +l 3348447418

Fax + I 3348443268

Email thangge@auburn.edu

\begin{abstract}
Type 2 diabetes is a chronic disease that requires several daily self-management decisions and complex care activities. Clinical management of diabetes and teaching patients diabetes self-management skills are necessary for optimal type 2 diabetes control. Diabetes self-management education (DSME) and support require time and resources. While there is a plethora of education material for health care professionals to use, very few guides compile the information in a practical way to relay the information to the patient. This quick guide to DSME has been developed to give physicians and their staff the tools to teach basic type 2 diabetes self-management skills in three 15-minute clinic visits.
\end{abstract}

Keywords: glycemic control, hemoglobin A1c, nutrition, exercise, blood glucose

\section{Introduction}

Diabetes self-management education (DSME) provides the foundation to help people with diabetes to incorporate and navigate treatment decisions and activities into their lives and has been shown to improve health outcomes. ${ }^{1-3}$ Studies have found that DSME is associated with improved diabetes knowledge and self-care behaviors, lower glycated hemoglobin or hemoglobin A1c (HbA1c) levels, lower self-reported weight, improved quality of life, healthy coping, and reduced health care costs. ${ }^{4,5}$ Delivery of medical nutrition therapy (MNT) by a registered dietitian is also associated with a decrease of about $0.5 \%-2 \%$ in $\mathrm{HbA} 1 \mathrm{c}$ in people with type 2 diabetes. ${ }^{6-8}$ Ideally, a primary care physician should have a registered dietitian or a diabetes education facility that he or she refers the patients for diabetes education. The 2017 Standards of Medical Care in Diabetes recommends that each person with diabetes should be actively engaged in education, self-management, and treatment planning with his or her health care team, including the collaborative development of an individualized eating plan. ${ }^{9} \mathrm{All}$ individuals with diabetes should receive individualized MNT from a registered dietitian. ${ }^{9}$ Often, DSME begins and ends with the primary care physician. However, the knowledge and support of a health care team is crucial for diabetes management.

It is important that each member of the health care team be knowledgeable about nutrition therapy principles for people with all types of diabetes and be supportive of their implementation. ${ }^{10}$ This quick guide to DSME has been developed to give physicians and their staff the tools to start teaching type 2 diabetes patients self-management skills in three 15-minute clinic visits in 2-4 week intervals. This process begins with the proper guidance from the primary care physician. The objective of this article is to present a quick guide to DSME for physicians and their staff to teach basic type 2 diabetes self-management 
skills in three 15-minute clinic visits. It is our perspective that physicians and their staff know how to treat diabetes, but this guide will help to present the self-management skills to patients in such a way that the latter can understand it and use it on a daily basis. This guide discusses a pathway of education that helps optimize glucose control for patients with type 2 diabetes.

\section{Importance of DSME}

By the most recent estimates, 30.3 million people in the US have diabetes ( $9.4 \%$ of the US population) and 84.1 million adults aged 18 years or older have prediabetes $333.9 \%$ of the adult US population). ${ }^{11,12}$ Consequently, more than 114 million Americans are at risk for developing the devastating complications of diabetes. ${ }^{11,12}$ DSME is a critical element of care for all people with diabetes and those at risk for developing the disease. It is necessary for them to learn how to manage diabetes and prevent/delay the complications. ${ }^{13,14}$

In a study by Alameddine et al, ${ }^{15} 332$ patients with type 2 diabetes completed a questionnaire, and although $75 \%$ of study participants believed that dietitians can assist them in changing their dietary habits, only $38 \%$ had consulted with a dietitian. Among the study's participants, only 34\% were referred to a dietitian by their physician. The main determinants of the use of dietary counseling services were referral by a physician, the presence of outpatient social or private health insurance, and the belief that a dietitian can assist in changing dietary habits. Dietitians can help patients achieve glucose control through individualized MNT and DSME. ${ }^{9}$ The physician's office is usually the home base for patients, and if the physician shows the importance of diet and exercise, as well as referral to a dietitian for individualized care, if available, patients can begin to take ownership of their health.

The primary care physician has the ability and influence to motivate his or her patients to learn more about diabetes and how to properly manage it. The first 6 months to 4 years of diagnosis are crucial to the long-term management of the disease. Laiteerapong et $\mathrm{al}^{16}$ from the Department of Medicine of the University of Chicago looked at the health records of $>28,000$ patients with type 2 diabetes to determine the HbA1c tracks for 10 years from the Kaiser Permanente health system in northern California. Patients who were unable to maintain their HbAlc levels had a higher chance of developing renal problems, eye disease, or lower-extremity amputation, as well as an increase in mortality risk. ${ }^{16}$ Hence, it is important for patients to maintain glycemic control after being diagnosed. Proper education and early management can help to decrease complications. It is necessary for the physician and his or her staff to provide diabetes education to patients so that they can achieve glycemic control.
The specific goals of DSME are as follows: teaching the basic concepts of type 2 diabetes, identifying and counting carbohydrates, maintaining a healthy body weight, exercising regularly, and monitoring and controlling blood sugars. ${ }^{9}$ These concepts need to be taught according to the specific needs of each patient. The dietitian or certified diabetes educator (CDE) can counsel the patient individually to discuss ways to incorporate all of these concepts into their daily routine. They can provide patients with practical tools for day-to-day meal planning rather than focusing on individual nutrients. This helps patients create a new future lifestyle vs a short-term diet. The partnership between physician and registered dietitian can help to inform patients regarding all the important topics related to diabetes.

\section{Quick overview of DSME}

This guide covers the 3 main topics of DSME: nutrition education, exercise, and medications (Figure 1). The goals of the first 15-minute visit are to give a basic understanding of diabetes, the patient's type of diabetes, basic carbohydrate counting, and normal glucose levels before and after meals. The goals of the second 15-minute visit are to explain the importance of exercise, hypoglycemia, and hyperglycemia and thereafter guide them what to do during low- and high-blood-sugar level conditions. In the third 15-minute visit, a review of the home-based glucose monitoring $\log$ and the food $\log$ is conducted, and thereafter, questions are answered and recommendations are provided.

\section{Visit I: day of diagnosis}

The first 15-minute clinic visit consists of a brief explanation of diabetes, carbohydrates, and meal planning. Here is a sample narrative.

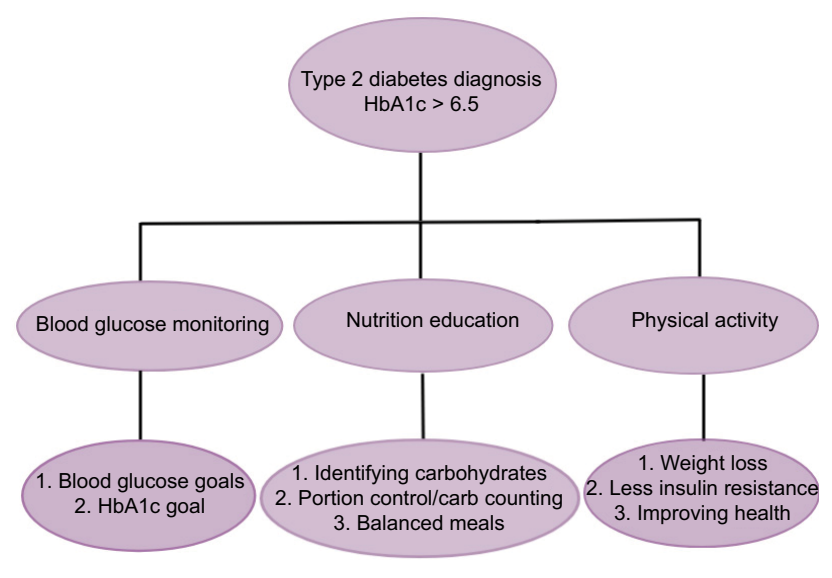

Figure I Flow diagram of the main topics of diabetes self-management education. Abbreviations: $\mathrm{HbAlc}$, hemoglobin Alc; Carb, carbohydrate. 
In general there are two types of diabetes mellitus. In type 1 diabetes, the body essentially stops making insulin, which is required for the cells to use the carbohydrates we eat. In type 2 diabetes, the body does not respond well to the insulin..$^{17}$ The diagnosis of type 2 diabetes is based on the fasting blood sugar being $>126 \mathrm{mg} / \mathrm{dL}$ and/or your HbA1c being $>6.5 \% .{ }^{18} \mathrm{The} \mathrm{HbA} 1 \mathrm{c}$ correlates with your average blood sugar over the past 3 months.

The nurse or medical assistant needs to teach the patient how to use the home-based glucose monitor and explain about the normal blood glucose levels before and after meals, as well as instruct on the recommended $\mathrm{HbAlc}$ levels (Table 1).

In type 2 diabetes, the body is unable to use insulin properly, so the amount of carbohydrates in each meal should be monitored. Carbohydrates are the only food group that increases blood sugar because the carbohydrates get converted to sugar, or glucose, in the body. Carbohydrates (bread, rice, potatoes, pasta, fruit, sugar, regular sweetened beverages, are few examples) raise blood sugar, but, in proper portions, help to maintain normal blood sugar level. Switching from sugary drinks to calorie/carbohydrate-free drinks, such as exchanging sweet tea to unsweetened tea; or crystal light/regular sodas to diet sodas; or lemonades to water, eliminates the carbohydrates in the beverages. Making these changes can help with weight loss and lowering of blood sugar levels. The sample meal plan (Figure 2) will help the patients to understand portion sizes of carbohydrate foods. To maintain good control of blood glucose levels, the amount of carbohydrates that the patient eats is very important; a man can eat around $60 \mathrm{~g}$ and women about $50 \mathrm{~g}$ of carbohydrates a meal. ${ }^{19}$ The patients should be provided a list of foods that are portioned to have $15 \mathrm{~g}$ of carbohydrates. Note that green leafy vegetables have few carbohydrates.

For instance, suppose a person eats the following breakfast: 1 cup oatmeal, 1 banana, and 1 scrambled egg. Egg is protein and does not count as carbohydrates. Moreover, 1 cup of oatmeal has $30 \mathrm{~g}$ carbohydrates and 1 banana also

Table I Blood glucose and hemoglobin AIc levels

\begin{tabular}{|l|l|l|l|}
\hline & $\begin{array}{l}\text { Blood } \\
\text { glucose } \\
\text { fasting } \\
\text { (mg/dL) }\end{array}$ & $\begin{array}{l}\text { Blood } \\
\text { glucose } \\
\text { 2 hours } \\
\text { after } \\
\text { eating } \\
\text { (mg/dL) }\end{array}$ & $\begin{array}{l}\text { Hemoglobin } \\
\text { Alc } \\
\text { (\%) }\end{array}$ \\
\hline $\begin{array}{l}\text { Normal } \\
\text { Prediabetes }\end{array}$ & $\begin{array}{l}80-99 \\
100-125\end{array}$ & $\begin{array}{l}\mid 20-140 \\
140-160\end{array}$ & $\begin{array}{l}5.7 \text { or below } \\
\text { Diabetes }\end{array}$ \\
$\begin{array}{l}126 \text { or } \\
\text { above }\end{array}$ & $\begin{array}{l}200 \text { or } \\
\text { above }\end{array}$ & 6.5 or above \\
\hline
\end{tabular}

has $30 \mathrm{~g}$ carbohydrates, so the breakfast will have a total of $60 \mathrm{~g}$ of carbohydrates. For lunch, if we consume meat, it is always better to have it baked, grilled, or boiled, and not fried. When it is fried, the flour on the meat will add carbohydrates to them. The meat is protein and does not have carbohydrates. Two slices of wheat bread (each slice has 15 $\mathrm{g}$ of carbohydrates) account for $30 \mathrm{~g}$ carbohydrates. Turkey or any unfried meat has $0 \mathrm{~g}$ carbohydrates, vegetables such as lettuce, broccoli, and tomato have very few carbohydrates, and one apple has $15 \mathrm{~g}$. Thus, the total amount of carbohydrates in the lunch will be $60 \mathrm{~g}$ (Figure 2). This example needs to be explained to the patients so that they use it and plan the menu for each meal every day. They should also be guided to maintain both a food log/journal and a homebased glucose monitoring log and bring it during their next visit within 2-4 weeks.

\section{Visit 2: implementation of physical activity in addition to food and blood sugar log review}

Any questions by the patients should be answered in this visit. Their blood sugar log and food log should be reviewed. Hypoglycemia and hyperglycemia should be explained in detail and they should be guided on what to do during low- and high-blood-sugar states. The importance of exercise, in addition to monitoring of eating habits, needs to be emphasized in this visit. Exercise is important for everyone, and the US Department of Health and Human Services recommends, in its physical activity guidelines for Americans, that adults over the age of 18 years do $150 \mathrm{~min} /$ week of moderate-intensity exercise and 2 days of muscle resistance training. ${ }^{20}$ According to the Standards of Medical Care in Diabetes, clinical trials have provided strong evidence for the $\mathrm{HbAlc}$-lowering value of resistance training in older adults with type 2 diabetes and for an additive benefit of combined aerobic and resistance exercise in adults with type 2 diabetes. ${ }^{15,21}$ One of the main goals of the diabetes prevention program is to exercise for at

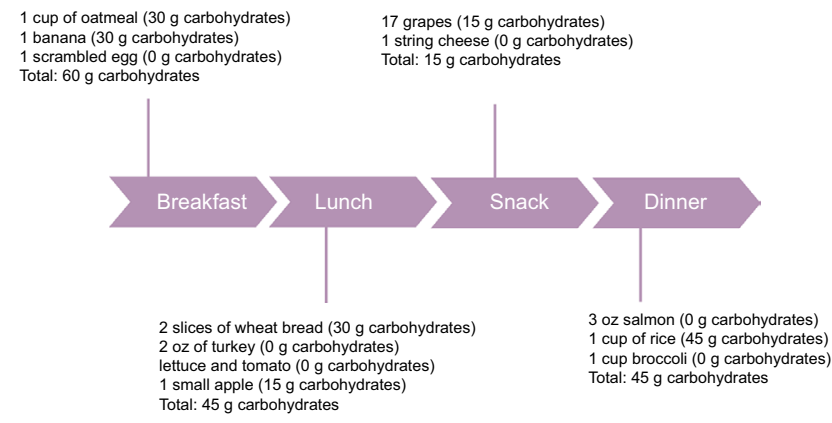

Figure 2 Sample meal plan for diabetes patients to control the intake of carbohydrates. 
least 150 minutes every week and lose at least 3\% of total body weight. These results have been proven to lower HbAlc levels and prevent type 2 diabetes. ${ }^{22}$ Insulin sensitivity is increased during exercise, so muscle cells are better able to use any available insulin to take up glucose during and after activity. ${ }^{24}$ When muscles contract during activity, the cells are able to convert glucose and use it for energy whether insulin is available or not. These benefits, plus the effects of the possible weight loss, can assist in normalizing blood sugars. ${ }^{23,24}$ The patients need to be asked to exercise regularly, such as walk for 20-30 minutes at least 3-4 days a week. They also need to be guided to continue to maintain the food log and glucose level monitoring log and bring it during their next visit.

\section{Visit 3: review and answering patient questions}

Any questions from the patients should be answered. Their blood sugar log and food log should be reviewed. Medications should be adjusted if needed after reviewing the logs and the result of the new $\mathrm{HbAlc}$ test. The third visit is also a great time to reinforce the importance of meeting with a registered dietitian and attending diabetes education classes. Individualized counseling and group education have been proven to be beneficial to all patients with diabetes. ${ }^{9}$ The patients should be advised to continue to maintain healthy eating, exercise, and medications. Encouragement and ongoing support are also crucial as things change in a patients' condition, and motivation can sometimes diminish. Patients should return at least every 3-6 months for a new HbA1c laboratory test, as well as receive ongoing updates and support from their coach. There are also resources for support groups and diabetes centers in some cities.

\section{Conclusion}

This guide was created to help health care professionals and office staff educate patients with type 2 diabetes. This gives them a sample narrative to use and make into their own. Combining the knowledge of the physician and the registered dietitian can help patients to reach optimal diabetes control in order to prevent or minimize complications. This guide provides the dialogue that is often missing in short physician visits. The physician can assist in setting the tone for how serious the patients take their diagnosis and how hard they work to achieve optimal blood glucose control. Nutrition and diabetes education are crucial to managing type 2 diabetes. Carbohydrate portioning, blood sugar monitoring, and exercise are some of the key topics that each patient should be fully knowledgeable about while managing his or her diabetes. This guide can be used to train physicians and their staff on the topics to discuss with their patients while in their clinics.

\section{Acknowledgment}

We would like to thank the Department of Nutrition, Dietetics, and Hospitality Management, as well as the College of Human Sciences, Auburn University for the startup funds contributed to TG.

\section{Disclosure}

The authors report no conflicts of interest in this work.

\section{References}

1. Powers MA, Bardsley J, Cypress M, et al. Diabetes self-management education and support in type 2 diabetes: A joint position statement of the American diabetes association, the American association of diabetes educators, and the academy of nutrition and dietetics. Clin Diabetes. 2016;34(2):70-80.

2. Brunisholz KD, Briot P, Hamilton $\mathrm{S}$, et al. Diabetes self-management education improves quality of care and clinical outcomes determined by a diabetes bundle measure. J Multidiscip Healthc. 2014;7:533-542.

3. Duncan I, Birkmeyer C, Coughlin S, et al. Assessing the value of diabetes education. Diabetes Educ. 2009;35(5):752-760.

4. Norris SL, Lau J, Smith SJ, Schmid CH, Engelgau MM. Self-management education for adults with type 2 diabetes: a meta-analysis of the effect on glycemic control. Diabetes Care. 2002;25(7):1159-1171.

5. Chrvala CA, Sherr D, Lipman RD. Diabetes self-management education for adults with type 2 diabetes mellitus: a systematic review of the effect on glycemic control. Patient Educ Couns. 2016;99(6): 926-943.

6. Marincic PZ, Hardin A, Salazar MV, Scott S, Fan SX, Gaillard PR. Diabetes self-management education and medical nutrition therapy improve patient outcomes: A pilot study documenting the efficacy of registered dietitian nutritionist interventions through retrospective chart review. J Acad Nutr Diet. 2017;117(8):1254-1264.

7. Ziemer DC, Berkowitz KJ, Panayioto RM, et al. A simple meal plan emphasizing healthy food choices is as effective as an exchange-based meal plan for urban African Americans with type 2 diabetes. Diabetes Care. 2003;26(6):1719-1724.

8. Wolf AM, Conaway MR, Crowther JQ, et al. Translating lifestyle intervention to practice in obese patients with type 2 diabetes: Improving control with activity and nutrition (ICAN) study. Diabetes Care. 2004;27(7):1570-1576.

9. American Diabetes Association. Standards of medical care in diabetes-2018. Diabetes Care. 2018;41(Suppl 1):S38-S50.

10. Centers for Disease Control and Prevention. National Diabetes Statistics Report; 2017. Available from: https://www.cdc.gov/diabetes/pdfs/data/ statistics/national-diabetes-statistics-report.pdf. Accessed October 04, 2018.

11. Haas L, Maryniuk M, Beck J, et al. National standards for diabetes self-management education and support. Diabetes Educ. 2012;38(5):619-629.

12. Beck J, Greenwood DA, Blanton L, et al. 2017 National standards for diabetes self-management education and support. Diabetes Educ. 2018;44(1):35-50.

13. Evert AB, Boucher JL, Cypress M, et al. Nutrition therapy recommendations for the management of adults with diabetes. Diabetes Care. 2013;36(11):3821-3842.

14. Franz MJ, Powers MA, Leontos C, et al. The evidence for medical nutrition therapy for type 1 and type 2 diabetes in adults. J Am Diet Assoc. 2010;110(12):1852-1889. 
15. Alameddine M, Nasreddine L, Hwalla N, et al. Factors associated with consulting a dietitian for diabetes management: a cross-sectional study. BMC Health Serv Res. 2013;13:504.

16. Laiteerapong N, Karter AJ, Moffet HH, et al. Ten-year hemoglobin A1c trajectories and outcomes in type 2 diabetes mellitus: The Diabetes \& Aging Study. J Diabetes Complications. 2017;31(1):94-100.

17. National Institute of Diabetes and Digestion and Kidney Disease [webpage on the Internet]. National Institute of Health; 2016. Available from: https:/www.niddk.nih.gov/health-information/diabetes/overview/ what-is-diabetes. Accessed September 24, 2018.

18. Handelsman Y, Bloomgarden ZT, Grunberger G, et al. American Association of Clinical Endocrinologists and American College of Endocrinology - clinical practice guidelines for developing a diabetes mellitus comprehensive care plan - 2015. Endocr Pract. 2015;21(Suppl 1):1-87.

19. Wheeler ML, Daly A, Evert A, et al. Choose your foods: exchange lists for diabetes, sixth edition, 2008: Description and guidelines for use. $J$ Am Dietetic Assoc. 2008;108:883-888.
20. Office of Disease Prevention and Health Promotion [webpage on the Internet]. Physical Activity Guidelines for Americans [Internet]. U. S. Department of Health and Human Services; 2008. Available from. http://www.health.gov/paguidelines/guidelines/default.aspx. Accessed September 24, 2018.

21. Colberg SR, Sigal RJ, Fernhall B, et al. Exercise and type 2 diabetes: the American College of Sports Medicine and the American Diabetes Association: joint position statement executive summary. Diabetes Care. 2010;33(12):2692-2696.

22. Sigal RJ, Kenny GP, Wasserman DH, Castaneda-Sceppa C. Physical activity/exercise and type 2 diabetes. Diabetes Care. 2004;27(10):2518-2539.

23. Church TS, Blair SN, Cocreham S, et al. Effects of aerobic and resistance training on hemoglobin A1c levels in patients with type 2 diabetes: a randomized controlled trial. JAMA. 2010;304(20):2253-2262.

24. American Diabetes Association [webpage on the Internet]. Blood Glucose and Exercise; 2017. Available from: http://www.diabetes.org/ food-and-fitness/fitness/get-started-safely/blood-glucose-control-andexercise.html. Accessed September 25, 2017
Diabetes, Metabolic Syndrome and Obesity: Targets and Therapy is an international, peer-reviewed open-access journal committed to the rapid publication of the latest laboratory and clinical findings in the fields of diabetes, metabolic syndrome and obesity research. Original research, review, case reports, hypothesis formation, expert

\section{Dovepress}

opinion and commentaries are all considered for publication. The manuscript management system is completely online and includes a very quick and fair peer-review system, which is all easy to use. Visit http://www.dovepress.com/testimonials.php to read real quotes from published authors.

Submit your manuscript here: https://www.dovepress.com/diabetes-metabolic-syndrome-and-obesity-targets-and-therapy-journal 